\title{
Recurrent dramatic QT prolongation in a patient with the sickle cell disease
}

\author{
Patrick Mathias ${ }^{1,2 *}$, Ben Abraham ${ }^{2}$ and Jooby John ${ }^{2}$ \\ ${ }^{1}$ Assistant Professor of Medicine, University of central Florida, Orlando, Florida, USA \\ ${ }^{2}$ Cardiovascular Associates, Kissimmee, Florida, USA
}

\begin{abstract}
Acquired long QT syndrome, occurs in $0.7 \%$ of hospitalizations. However, recurrent acquired long QT syndrome, during the same hospitalization is quite rare. We report the unusual case of a patient with sickle cell disease who developed symptomatic QT interval prolongation, that occurred despite documented normalization of electrolytes, and absence of any QT prolonging medications. We provide hypotheses to explain the phenomenon, including, the presence of sickle cell disease, genetic predisposition, transient elevation of pulmonary artery pressures, and episodic elevation of vagal tone.
\end{abstract}

\section{Introduction}

Acquired long QT syndrome occurs in $0.7 \%$ of hospitalizations [1]. It is frequently provoked by electrolyte abnormalities, in combination with administration of certain medications. [2]. We report the unusual case of an 18-year-old African-American female with the sickle cell disease, who, during a recent hospitalization, developed symptomatic QT interval prolongation. This QT interval prolongation, recurred, transiently, even after complete correction of electrolyte abnormalities, and discontinuation of all medications that could provoke QT interval prolongation.

\section{Case description}

An 18-year-old African American female, with a past history of sickle cell disease, hemoglobin SS type, presented to the emergency room complaining of severe generalized body pain. The serum potassium on admission was 4.5, and her EKG was normal. Patient was evaluated and treated for acute sickle cell crisis with hydration and pain control. She developed evidence of pneumonia and required endotracheal intubation. On the seventh day of hospitalization, she developed dramatic QT interval prolongation, with polymorphic ventricular ectopy, and a classical long short sequence (Figure 1). Her potassium and magnesium levels were aggressively corrected. Her troponin $\mathrm{T}$ was $<0.01$. All potential QT interval prolonging medications were discontinued. The QT interval normalized, the next day (Figure 2). Patient was extubated and made a complete clinical recovery. Three days later, she redeveloped dramatic QT interval prolongation (Figure 3 ). At this time, her electrolytes were completely normal, and she was on no potential QT prolonging drugs. Her QT interval, normalized spontaneously, in 2 hours (Figure 4). Unfortunately, the patient refused consent for genetic testing.

\section{Discussion}

The QT interval is heart rate dependent, and the Bazett formula [3] has been used since the 1920s, in spite of valid criticisms [4]. The long QT syndrome is frequently associated with sinus bradycardia, since, various types of long QT syndrome gene mutations, are also expressed in the human SA node [5]. Vagally mediated bradycardia is felt to have a disproportionate effect on QT prolongation [6,7]. Indeed, differences in vagal activity, are hypothesized to explain why some long QT syndrome family members carrying the same mutation, have divergent symptoms $[8,9]$.

Prolongation of the corrected QT interval, can occur in up to $33.1 \%$ of patients with sickle cell disease $[10,11]$. The level of QT prolongation, seen in this patient, has not been previously described. Also, this patient did not have any of the variables associated with a prolonged QT interval [10,12]. Her hemoglobin was 9.5. Cardiac autonomic neuropathy has been described in patients with sickle cell disease, predominantly affecting parasympathetic tone [13].

In summary, we believe that this patient exhibited "a perfect storm". This included a genetic predisposition with limited expression, (we suspect LQT1), transient elevation in pulmonary artery pressures due to pneumonia, and episodic elevation of vagal tone.

*Correspondence to: Patrick Mathias, Assistant Professor of Medicine, University of central Florida, Orlando, Florida, USA. Cardiovascular Associates, Kissimmee, Florida, USA, E-mail: indianpat127@yahoo.com

Key words: recurrent, acquired long QT syndrome, sickle cell disease, pulmonary artery pressures, elevation of vagal tone

Received: August 10, 2020; Accepted: August 24, 2020; Published: August 31, 2020 


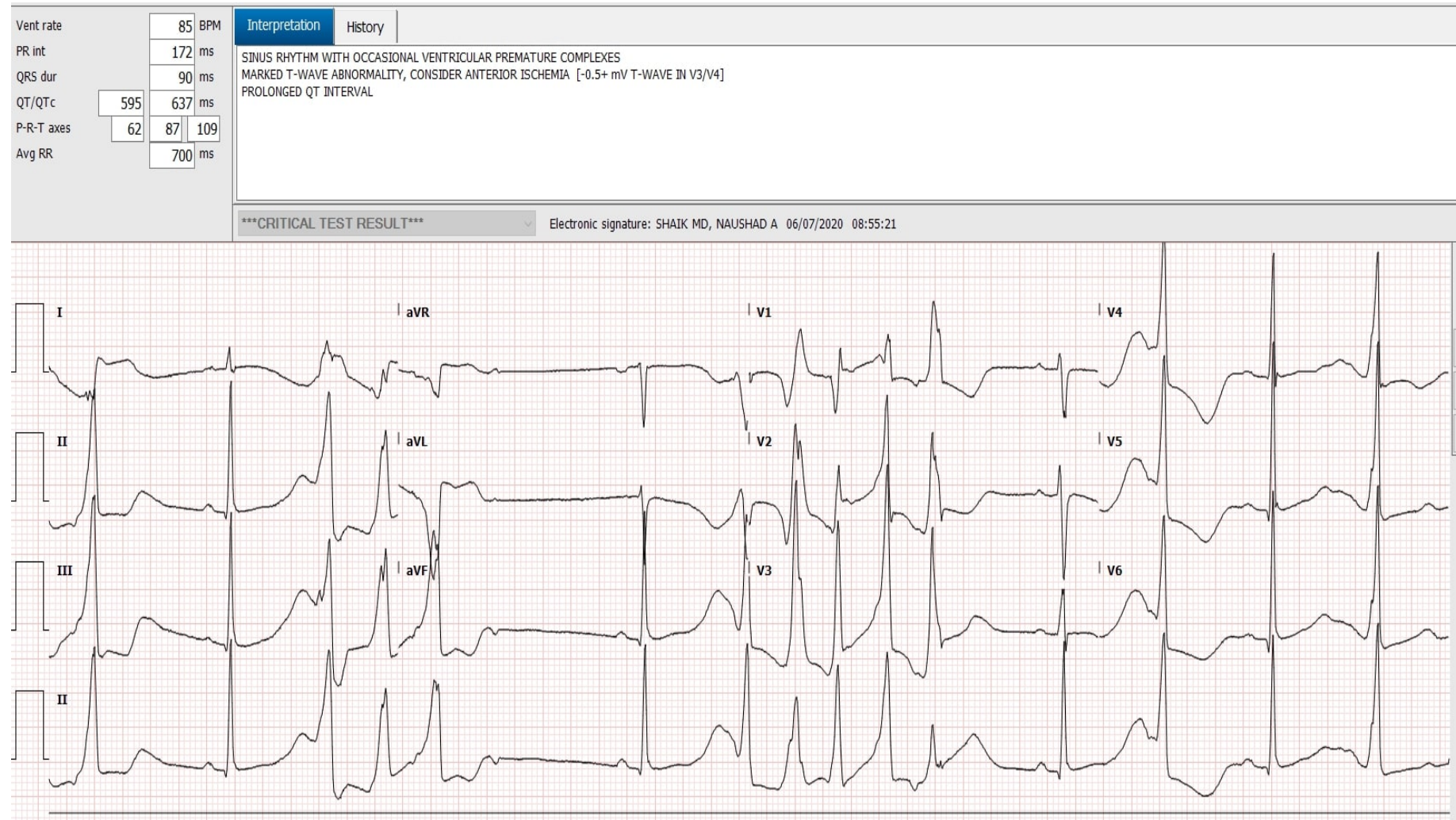

Figure 1. QT interval prolongation, with polymorphic ventricular ectopy, and a classical long short sequence

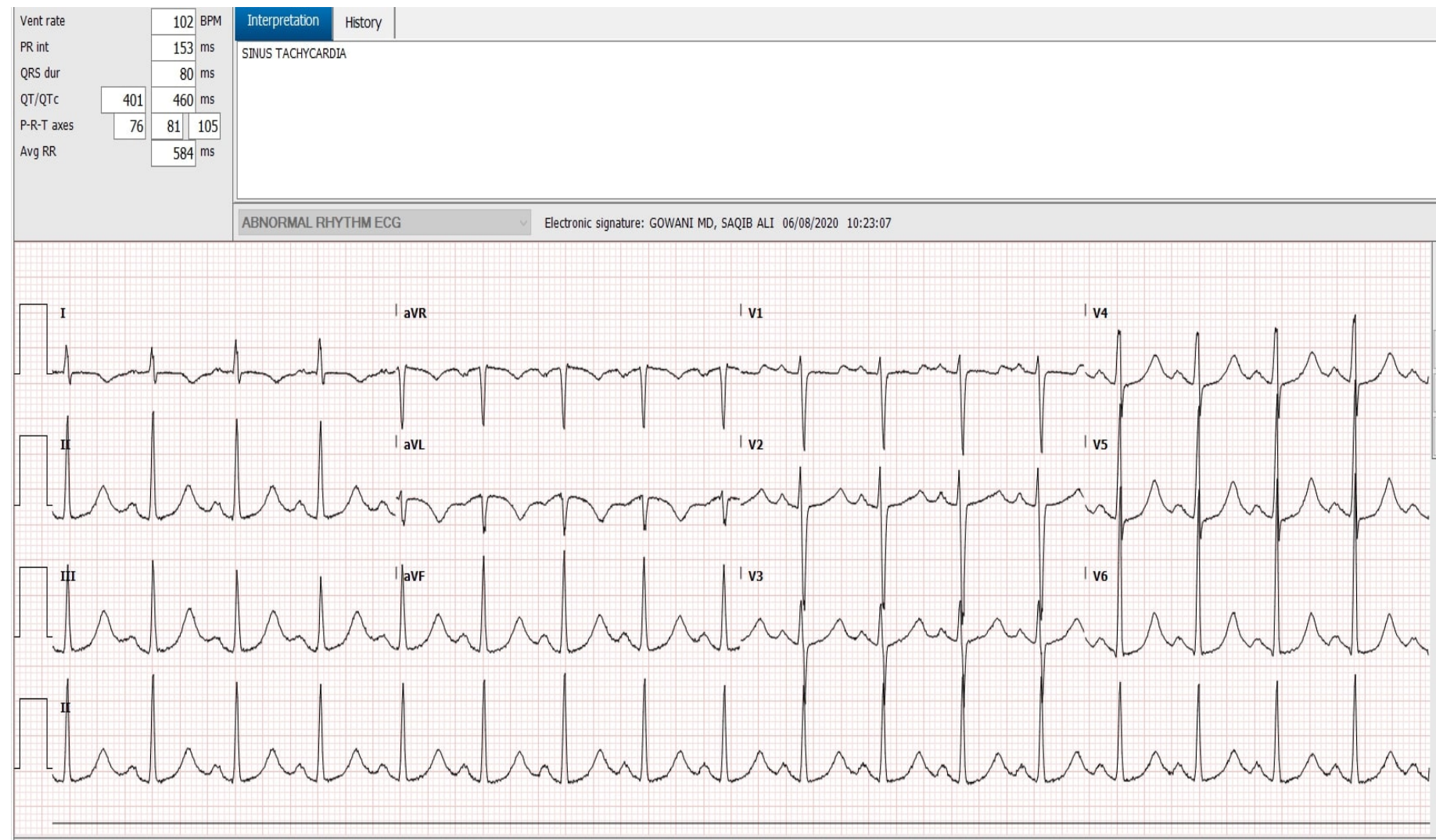

Figure 2. Abnormal QT interval prolongation 


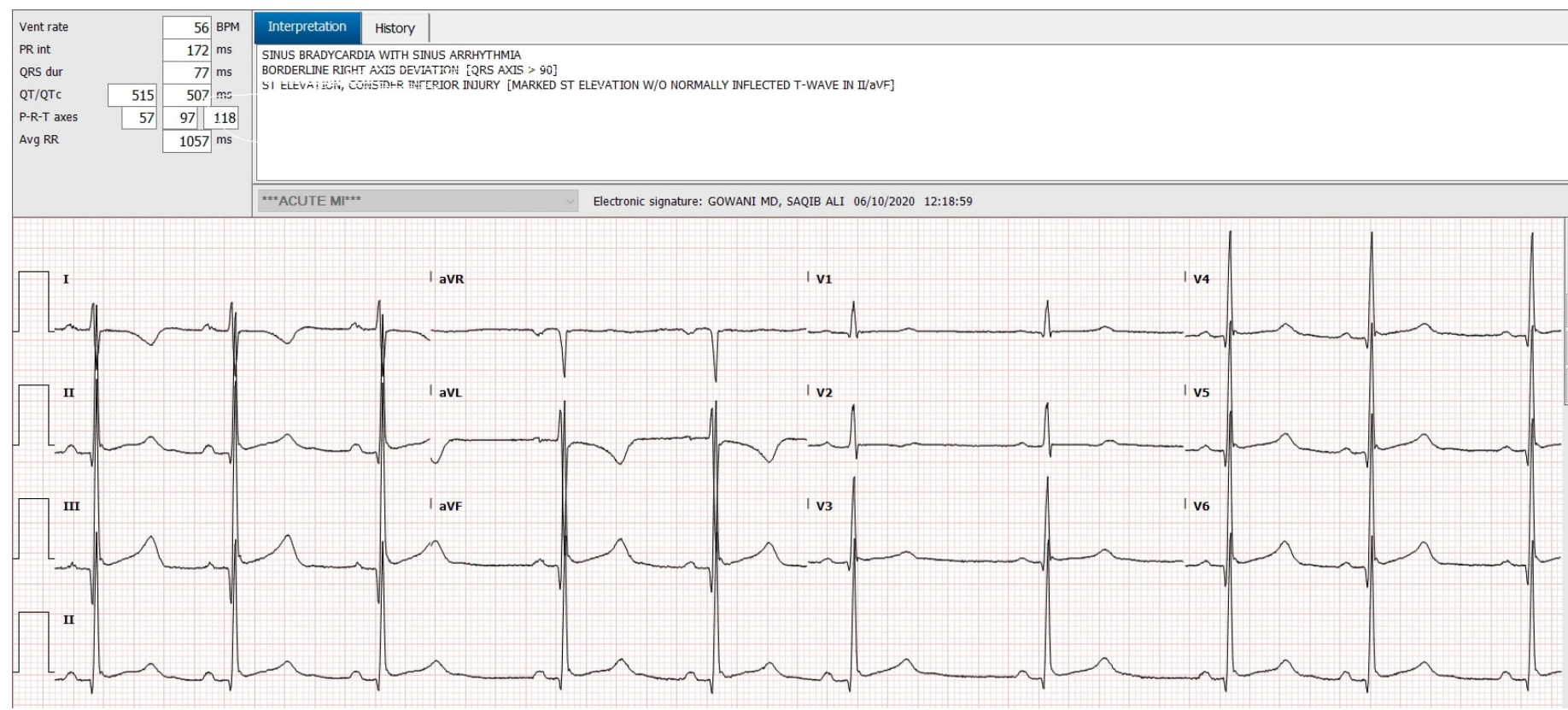

Figure 3. Dramatic QT interval prolongation

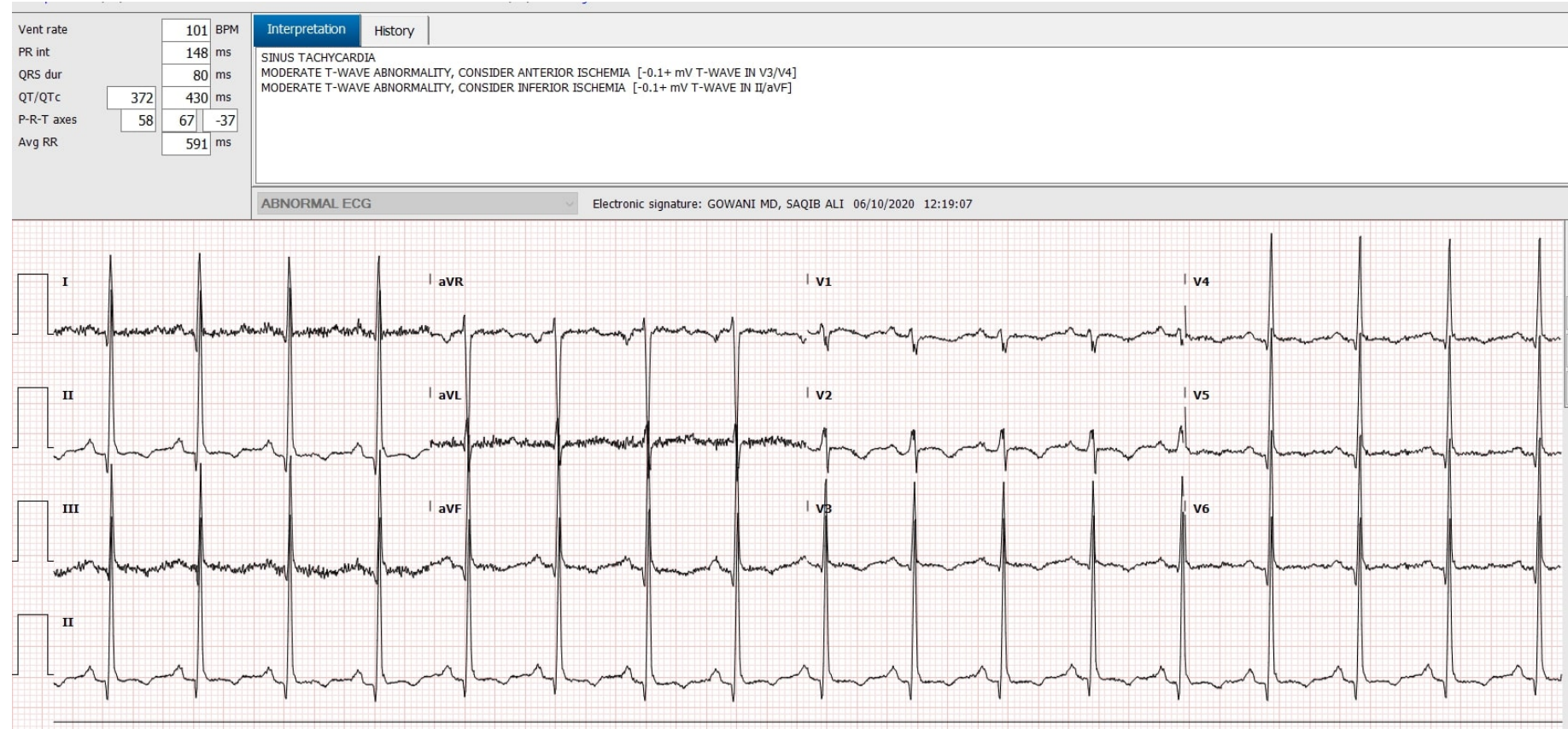

Figure 4. QT interval normalized spontaneously in 2 hours

\section{References}

1. Yu H, Zhang L, Liu J, Liu Y, Kowey PR, et al. (2017) Acquired long QT syndrome in hospitalized patients. Heart Rhythm 14: 974. [Crossref]

2. Goldenberg I, Zareba W, Moss AJ (2003) Long QT syndrome. JAMA 284: 2041-2044. [Crossref]

3. Bazett HC (1920) An analysis of the time-relations of electrocardiograms. Heart 7: 353-370.

4. Indik JH, Pearson EC, Fried K, Woosley RL (2008) Bazett and Fridericia QT correction formulas interfere with measurements of drug-induced changes in QT interval. Heart Rhythm 3: 1003-1007. [Crossref]

5. Wilders R, Verkerk AO (2018) Long QT syndrome and sinus bradycardia-a mini review. Front Cardiovasc Med 3: 106. [Crossref]
6. Cappato R, Alboni P, Pedroni P, Gilli G, Antonioli GE (1991) Sympathetic and vagal influences on rate-dependent changes of QT interval in healthy subjects. Am Coll Cardiol 68: 8-93.

7. Farkas A, Dempster J, Coker SJ (2008) Importance of vagally mediated bradycardia for the induction of torsade de pointes in an in vivo model. Br J Pharmacol 154: 958-970. [Crossref]

8. Porta A, Girardengo G, Bari V, George AL, Brink PA, et al. (2015) Autonomic contro of heart rate and of QT interval variability, influences arrhythmic risk in long QT syndrome type I. J Am Coll Cardiol 3: 367-374. [Crossref]

9. Crotti L, Spazzolini C, Porretta AP, Dagradi F, Taravelli E, et al. (2012) Vagal reflexes following an exercise stress test: A simple clinical tool for gene-specific risk stratification in the long QT syndrome. J Am Coll Cardiol 60: 2515-2524. [Crossref] 
10. Goel R, Rajderkar S, Padman R, Krishnamurti L (2010) Prolonged QTc interval is common in patients with sickle cell disease and has an inverse relationship to hemoglobin and hematocrit: Results from CSSCD. Blood 116: 2675.

11. Indik JH, Nair V, Rafikov R, Nyotowidjojo IS, Bisla J, et al. (2016) Associations of prolonged QTc in sickle cell disease. Plos One 11: e0164526. [Crossref]
12. Liem RI, Young LT, Thompson AA (2009) Prolonged QTc interval in children and young adults with sickle cell disease at steady state. Pediatr Blood Cancer 52: 842846. [Crossref]

13. Kolo PM, Sanya EO, Olanrewaju TO, Fawibe AE, Soladoye A (2013) Cardiac autonomic dysfunction in sickle cell anaemia and its correlation with QT parameters. Niger Med J 54: 382-385. [Crossref]

Copyright: $\odot 2020$ Mathias P. This is an open-access article distributed under the terms of the Creative Commons Attribution License, which permits unrestricted use, distribution, and reproduction in any medium, provided the original author and source are credited. 